\title{
Promoter methylation status of the tumor suppressor genes p16 and cadherin 1 in cervical intraepithelial neoplasia
}

\author{
RUEI-NIAN LI ${ }^{1}$, CHIEN-YU LI ${ }^{1}$, CHIEN-HUNG LEE ${ }^{2}$, CHIUNG-YU PENG $^{2}$ and MING-TSANG WU ${ }^{3,4}$ \\ Departments of ${ }^{1}$ Biomedical Science and Environmental Biology, and ${ }^{2}$ Public Health; \\ ${ }^{3}$ Graduate Institute of Occupational Safety and Health and Research Center of Excellence for \\ Environmental Medicine, Kaohsiung Medical University; ${ }^{4}$ Department of Family Medicine, Kaohsiung \\ Medical University Hospital, Kaohsiung Medical University, Kaohsiung 100044, Taiwan, R.O.C.
}

Received February 19, 2016; Accepted February 3, 2017

DOI: $10.3892 / \mathrm{ol} .2017 .5975$

\begin{abstract}
Cervical cancer is the second most common female cancer worldwide. DNA methylation is one of a number of epigenetic regulation mechanisms leading to gene silencing in neoplastic cells. Aberrant methylation results in the silencing of tumor suppressor gene expression, and has been detected in a high percentage of human cancers. In the present study, the methylation status of three tumor suppressor genes, retinoic acid receptor $\beta$ (RAR $\beta)$, p16 and cadherin 1 (CDH1), and the inflammatory-associated cyclooxygenase-2 (COX-2) gene, was examined at distinct stages of cervical intraepithelial neoplasia (CIN). The results of the present study revealed that the COX-2 gene was unmethylated between CIN I and carcinoma specimens. The RAR $\beta$ gene exhibited a minimal change in methylation frequency, whereas the CDH1 methylation level was increased $<2$-fold between CIN I and carcinoma. Notably, the methylation frequency of p16 was $13.2 \%$ in normal specimens; $18.2 \%$ in CIN I; $35.7 \%$ in CIN II; $31.6 \%$ in CIN III; and $15.4 \%$ in carcinoma. By contrast, the methylation frequency of p16 increased between CIN I and carcinoma in the absence of high-risk group papillomaviruses. The results of bisulfite sequencing indicated that the $10 \mathrm{CpG}$ sites were all methylated in p16 gene methylation-positive individuals. The results of the present study demonstrate that the methylation frequency of p16 and CDH1 was progressively increased during the development of malignant stages in CIN, and may be an additional tool for current cytomorphology-based screening of cervical cell specimens.
\end{abstract}

\section{Introduction}

Cervical cancer is the leading cause of female cancer worldwide $(1,2)$. The incidence rate of cervical cancer is high in

Correspondence to: Dr Ming-Tsang Wu, Graduate Institute of Occupational Safety and Health and Research Center of Excellence for Environmental Medicine, Kaohsiung Medical University, Room 721 CS Building, 100 Shih-Chuan 1st Road, Kaohsiung 100044, Taiwan, R.O.C. E-mail: 960021@ms.kmuh.org.tw

Key words: gene methylation, cervical intraepithelial neoplasia, tumor suppressor gene developing countries. High-risk group (HR) papillomaviruses (HPV) have been characterized as the etiological agents of cervical cancer. HPV-infected cells may develop into non-invasive or pre-malignant lesions referred to as cervical intraepithelial neoplasia (CIN), also termed squamous intraepithelial lesions. The classification of CIN depends on the morphological alteration in pre-malignant lesion cells. CIN I and CIN II are mildly dysplastic and rarely progress towards carcinoma, whereas CIN II and CIN III lesions are precursors of cervical cancer due to the proliferation of dysplastic cells. The development of cervical carcinoma is established from high-grade squamous intraepithelial neoplasms, which are frequently identified by exfoliative cytology screening (conventional Pap smear) $(3,4)$. If not treated, $>25 \%$ of early lesions progress to carcinoma in situ or invasive cancer (5).

The methylation of cytosine in $\mathrm{CpG}$ dinucleotides is an epigenetic gene-regulation mechanism in mammalian genomes. The methylation of gene sequences subsequently results in the inactivation of gene expression $(6,7)$. Aberrant methylation of tumor suppressor genes has been detected in a high proportion of human cancers (8). It has been identified in almost all types of cancer and contributes to malignant transformation by silencing multiple tumor suppressor genes. Numerous previous studies have investigated DNA methylation changes in cancer-associated gene sequences $(8,9)$. The aberrant methylation of tumor suppressor genes has been detected in gynecological malignancies (10-12). Wisman et al (13) proposed that hypermethylation analysis may eventually become an additional tool to identify patients with high-grade squamous intraepithelial neoplasms or invasive cervical cancer, due to its increased specificity compared with current cytomorphology-based screening (13).

In particular, changes in hypermethylation of promoter regions have been implicated in the onset and progression of cervical cancer. However, the frequencies of hypermethylation of tumor suppressor genes vary in the literature (14), and information concerning methylation genes is not well documented in precancer, including CIN II and CIN III. Therefore, the focus of the present study was on three tumor suppressor genes and an inflammation-associated gene, and the association between DNA methylation status and cytopathological features of the genes was investigated. 


\section{Materials and methods}

Clinical subjects. A community-based case-control study was conducted in Kaohsiung City, and 529 patients (mean age, 46.2 \pm 13.2 ) were enrolled in the present study between January 2008 and September 2010. The procedure of patient enrollment was as previously described (15). Cervical scrapings were obtained from female patients who attended the Department of Obstetrics and Gynecology, Kaohsiung Medical University Hospital (Kaohsiung, Taiwan) or from the community health clinics of Great Kaohsiung City (southern part of Taiwan). Specimens were screened for CIN by Pap smear, and the diagnosis was based on cervical cytomorphological and histological characteristics. Normal specimens were collected, as well as distinct stages of cervical neoplasm specimens, including CIN I, CIN II, CIN III and squamous cell carcinoma. The present study was approved by the Institutional Review Board of Kaohsiung Medical University Hospital, and informed consent was obtained from all patients.

Extraction of genomic DNA. Genomic DNA samples were collected from cervical scrapings. Cells from cervical scrapings were concentrated by centrifugation ( $425 \mathrm{x} g$ for $10 \mathrm{~min}$ at room temperature) and were solubilized in cell lysis solution (Cell lysis/binding buffer; Invitrogen; Thermo Fisher Scientific, Inc., Waltham, MA, USA). The cellular lysate was digested with $20 \mu \mathrm{g} / \mathrm{ml}$ proteinase $\mathrm{K}$ at $55^{\circ} \mathrm{C}$ overnight. DNA extraction was performed with a Genomic DNA Purification kit (Invitrogen; Thermo Fisher Scientific, Inc.), according to the manufacturer's protocol. The cellular DNA was finally dissolved in sterile water until subsequent reaction. The genomic DNA was also determined for human papillomavirus infection by screening HPV DNA using the Hybrid Capture II assay (Digene Corporation, Gaithersburg, MD, USA).

Bisulfite modification. The methylation status of the promoter regions was determined by sodium bisulfite reaction. The purified cellular DNA was added to a cytosine conversion reagent in the MethylCode Bisulfite Conversion kit (Invitrogen; Thermo Fisher Scientific, Inc.). Bisulfite treatment of DNA converted unmethylated cytosine into uracil, and methylated cytosine remained unchanged. DNA was treated with sodium bisulfite using the MethylCode Bisulfite Conversion kit, according to the manufacturer's protocol.

Methylation-specific polymerase chain reaction $(P C R)$. The primers and reaction conditions for p16, COX-2 and CDH1 were as described previously (16-18). The PCR thermocycling conditions for COX-2 was as follows: $94^{\circ} \mathrm{C}$ for $30 \mathrm{sec}, 53^{\circ} \mathrm{C}$ for $30 \mathrm{sec}$ and $72^{\circ} \mathrm{C}$ for $60 \mathrm{sec}$, for 40 cycles. The methylated primers for RARb were 5'-GGGGGATTAAATTTTTTA TGC-3' (forward) and 5'-AAATCCTACCCCGACGATAC-3' (reverse). The unmethylated primers for RARb were 5'-GGG GGATTAGAATTTTTTATGTGA-3' (forward) and 5'-AAA TCCTACCCCAACAATACC-3' (reverse). Bisulfite-modified DNA $(2 \mu \mathrm{l})$ was loaded in $25 \mu \mathrm{l}$ PCR mixture containing $1 \mathrm{X}$ PCR buffer, $0.2 \mu \mathrm{M}$ of each primer, $0.2 \mathrm{mM}$ dNTP, $1.5 \mathrm{mM}$ $\mathrm{MgCl}_{2}$ and 0.7 unit HotStart Taq polymerase (Promega
Corporation, Madison, WI, USA). The annealing temperature for $\mathrm{CDH} 1$ and RAR $\beta$ was initially $65^{\circ} \mathrm{C}$, decreasing by $1^{\circ} \mathrm{C}$ for each cycle until reaching $55^{\circ} \mathrm{C}$, and amplification was at $94^{\circ} \mathrm{C}$ for $30 \mathrm{sec}, 55^{\circ} \mathrm{C}$ for $30 \mathrm{sec}$ and $72^{\circ} \mathrm{C}$ for $60 \mathrm{sec}$. The amplified PCR products were visualized by $1.8 \%$ agarose gel electrophoresis. Either PCR products were cloned into pGem-T vectors (Promega Corporation) for automated sequencing, or direct sequencing was performed.

Statistical analysis. The statistical data were examined by $\chi^{2}$ test and Students t-test on Microsoft Excel software (2013; Microsoft Corporation, Redmond, WA, USA). Each experiment containing clinical samples was repeated three times. $\mathrm{P}<0.05$ was considered to indicate a statistically significant difference.

\section{Results}

The methylation status of three tumor suppressor genes, including RAR $\beta$, p16 and CDH1, and an inflammatory-associated COX-2 gene, were examined in distinct stages of CIN by methylation-specific PCR (Fig. 1).

The methylation rate of the COX-2 gene promoter was detected in $1.2 \%$ of normal specimens, but in $0 \%$ of CIN I, CIN II, CIN III and cervical squamous cell carcinoma. The results of the present study indicated that the COX-2 gene was in a hypomethylated or unmethylated form (Table I). It was observed that the RAR $\beta$ gene exhibited only a minimal change in methylation frequency (Table I). The methylation frequency of the CDH1 gene was 4.7 and $4.3 \%$ in normal and precancerous stage CIN I, respectively. By contrast, the methylation frequency was 7.1 and $7.9 \%$ in CIN II and CIN III, respectively. The CDH1 gene methylation level was markedly increased $<2$-fold between CIN I and carcinoma ( $\mathrm{P}=0.249$; Table I). This indicated that the increased frequency of promoter methylation was associated with increasing severity of cervical neoplasm changes. Notably, the methylation frequency of p16 was $13.2 \%$ in normal specimens; $18.2 \%$ in CIN I; $35.7 \%$ in CIN II; $31.6 \%$ in CIN III; and $15.4 \%$ in squamous cell carcinoma (Table I). The methylation frequency of p16 progressively increased during the development of malignant stages. Cervical specimens were screened for human papillomavirus (HPV) by the method of Hybrid Capture II (Digene Corporation). The results indicated that, particularly in the absence of HR-HPV, the methylation frequency of p16 was $11.8 \%$ in normal, $25 \%$ in CIN I and 58.3\% in CIN II-carcinoma. In the presence of HR-HPV, the methylation frequency of p16 was without any apparent change; $21.3 \%$ in normal, $13.8 \%$ in CIN I and 23.8\% for CIN II, CIN III and carcinoma (Table II).

There are $11 \mathrm{CpG}$ sites located within the PCR-amplified $150 \mathrm{bp}$ fragments of the p16 promoter, which encompass a number of distinct transcription factor-binding sites (Fig. 2A). The PCR-amplified DNA fragments were also cloned and sequenced following bisulfite treatment, and the methylation status of all CG sites in the promoter region was determined. The results from 10 individuals with CIN II and above identified complete methylation at each $\mathrm{CpG}$ site (Fig. 2B). Bisulfite sequencing also revealed that the $\mathrm{CpG}$ sites were all unmethylated from p16 unmethylated individuals (Fig. 2B). 
Table I. Methylation status of 4 distinct genes in distinct stages of cervical intraepithelial neoplasia.

\begin{tabular}{lccccc}
\hline Gene & $\begin{array}{c}\text { Normal, } \\
\text { frequency (\%) }\end{array}$ & $\begin{array}{c}\text { CIN I, } \\
\text { frequency }(\%)\end{array}$ & $\begin{array}{c}\text { CIN II, } \\
\text { frequency (\%) }\end{array}$ & $\begin{array}{c}\text { CIN III, } \\
\text { frequency (\%) }\end{array}$ & $\begin{array}{c}\text { Squamous cell } \\
\text { carcinoma, frequency (\%) }\end{array}$ \\
\hline RARß & $12 / 311(3.9)$ & $1 / 46(2.2)$ & $0 / 23(0.0)$ & $1 / 31(3.2)$ & $0 / 7(0.0)$ \\
p16 & $52 / 395(13.2)$ & $10 / 55(18.2)$ & $10 / 28(35.7)$ & $12 / 38(31.6)$ & $2 / 13(15.4)$ \\
CDH1 & $18 / 384(4.7)$ & $2 / 46(4.3)$ & $2 / 28(7.1)$ & $3 / 38(7.9)$ & $0 / 12(0.0)$ \\
COX-2 & $3 / 259(1.2)$ & $0 / 35(0.0)$ & $0 / 23(0.0)$ & $0 / 31(0.0)$ & $0 / 6(0.0)$ \\
\hline
\end{tabular}

RAR $\beta$, retinoic acid receptor $\beta$; CDH1, cadherin 1; COX-2, cyclooxygenase-2; CIN, cervical intraepithelial neoplasia.

Table II. Methylation frequency of p16 in HPV-negative and HPV-positive specimens.

\begin{tabular}{lcr}
\hline Grade & HPV-negative, frequency (\%) & HPV-positive, frequency (\%) \\
\hline Normal & $32 / 271(11.8)$ & $16 / 75(21.3)$ \\
CIN I & $6 / 24(25)$ & $4 / 29(13.8)$ \\
CIN II-carcinoma & $7 / 12(58.3)$ & $19 / 80(23.8)$ \\
P-value & 0.0018 & 0.6510 \\
\hline
\end{tabular}

CIN, cervical intraepithelial neoplasia; HPV, human papillomavirus.

\begin{tabular}{|c|c|c|c|c|c|c|c|c|c|}
\hline \multirow{6}{*}{$\mathbf{R A R} \boldsymbol{\beta}$} & & & \multicolumn{7}{|c|}{ Cervical specimens } \\
\hline & UC & MC & 1 & 2 & \multicolumn{2}{|r|}{3} & 4 & 5 & 6 \\
\hline & $\overline{\mathbf{U}} \mathbf{M}$ & $\overline{\mathbf{U}} \mathbf{M}$ & $\bar{U} \quad \mathbf{M}$ & $\bar{U} \mathbf{M}$ & $\mathrm{Mr}$ & $\bar{U} \quad \mathbf{M}$ & $\bar{U} \quad \mathbf{M}$ & $\bar{U} \quad \mathbf{M}$ & U $\quad \mathbf{M}$ \\
\hline & 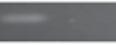 & - & $=$ & & \multicolumn{2}{|c|}{$\equiv$} & + & - & - \\
\hline & & & \multicolumn{7}{|c|}{ Cervical specimens } \\
\hline & UC & MC & 1 & 2 & & 3 & 4 & 5 & 6 \\
\hline \multirow{5}{*}{ p16 } & U $\quad \mathbf{M}$ & $\mathbf{U} \quad \mathbf{M}$ & U $\quad \mathbf{M}$ & $\mathbf{U} \quad \mathbf{M}$ & Mr & U $\quad \mathbf{M}$ & U $\quad \mathbf{M}$ & $\mathbf{U} \quad \mathbf{M}$ & U $\quad \mathbf{M}$ \\
\hline & & $=$ & & & $E$ & +2 & 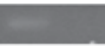 & +2 & -2 \\
\hline & & & \multicolumn{7}{|c|}{ Cervical specimens } \\
\hline & $\mathbf{U C}$ & MC & 1 & 2 & & 3 & 4 & 5 & 6 \\
\hline & $\mathbf{U} \quad \mathbf{M}$ & U $\mathbf{M}$ & U $\quad \mathbf{M}$ & $\mathbf{U} \quad \mathbf{M}$ & $\mathrm{Mr}$ & U $\quad \mathbf{M}$ & U $\quad \mathbf{M}$ & $\mathbf{U} \quad \mathbf{M}$ & U $\quad \mathbf{M}$ \\
\hline \multirow[t]{4}{*}{ CDH1 } & & $=$ & - & - & $\equiv$ & - & - & 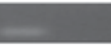 & \\
\hline & & & \multicolumn{7}{|c|}{ Cervical specimens } \\
\hline & UC & MC & 1 & 2 & & 3 & 4 & 5 & 6 \\
\hline & $\mathbf{U} \quad \mathbf{M}$ & $\mathbf{U} \quad \mathbf{M}$ & $\mathbf{U} \quad \mathbf{M}$ & U $\quad \mathbf{M}$ & $\mathrm{Mr}$ & $\mathbf{U} \quad \mathbf{M}$ & U $\quad \mathbf{M}$ & $\mathbf{U} \quad \mathbf{M}$ & U $\quad \mathbf{M}$ \\
\hline COX-2 & $=$ & $-=$ & $=$ & - & $\equiv$ & $=$ & $=$ & 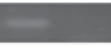 & 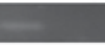 \\
\hline
\end{tabular}

Figure 1. The methylation-specific PCR results of 4 distinct genes in 6 cervical specimens. PCR, polymerase chain reaction; UC, unmethylated control; MC, methylated control; Mr, DNA marker; U, unmethylated PCR product; M, methylated PCR product; RAR $\beta$, retinoic acid receptor $\beta$; CDH1, cadherin 1; COX-2, cyclooxygenase- 2 .

\section{Discussion}

DNA methylation is an important epigenetic mechanism of transcriptional control. It performs a critical function in the regulation of cellular gene expression. Aberrant DNA methylation often occurs in numerous types of cancer; it contributes to malignant transformation by silencing multiple tumor suppressor genes. Therefore, DNA methylation has been increasingly recognized as a promising epigenetic and diagnostic biomarker (8). In the present study, the methylation status of tumor suppressor genes, including RAR $\beta, \mathrm{p} 16$ and CDH1, and an inflammatory-associated COX-2 gene, was analyzed in distinct stages of CIN using methylation-specific PCR. Retinoic acid is required for the regulation of epithelial cell differentiation (19). The RAR is an intracellular molecule responsible for the binding to the RAR-responsive element promoter (20). The rate of RAR $\beta$ methylation was progressively increased during oncogenesis of the cervix (11). In the present study, the RAR $\beta$ promoter exhibited a minimal change in methylation rate, and no significant difference was observed in the methylation 


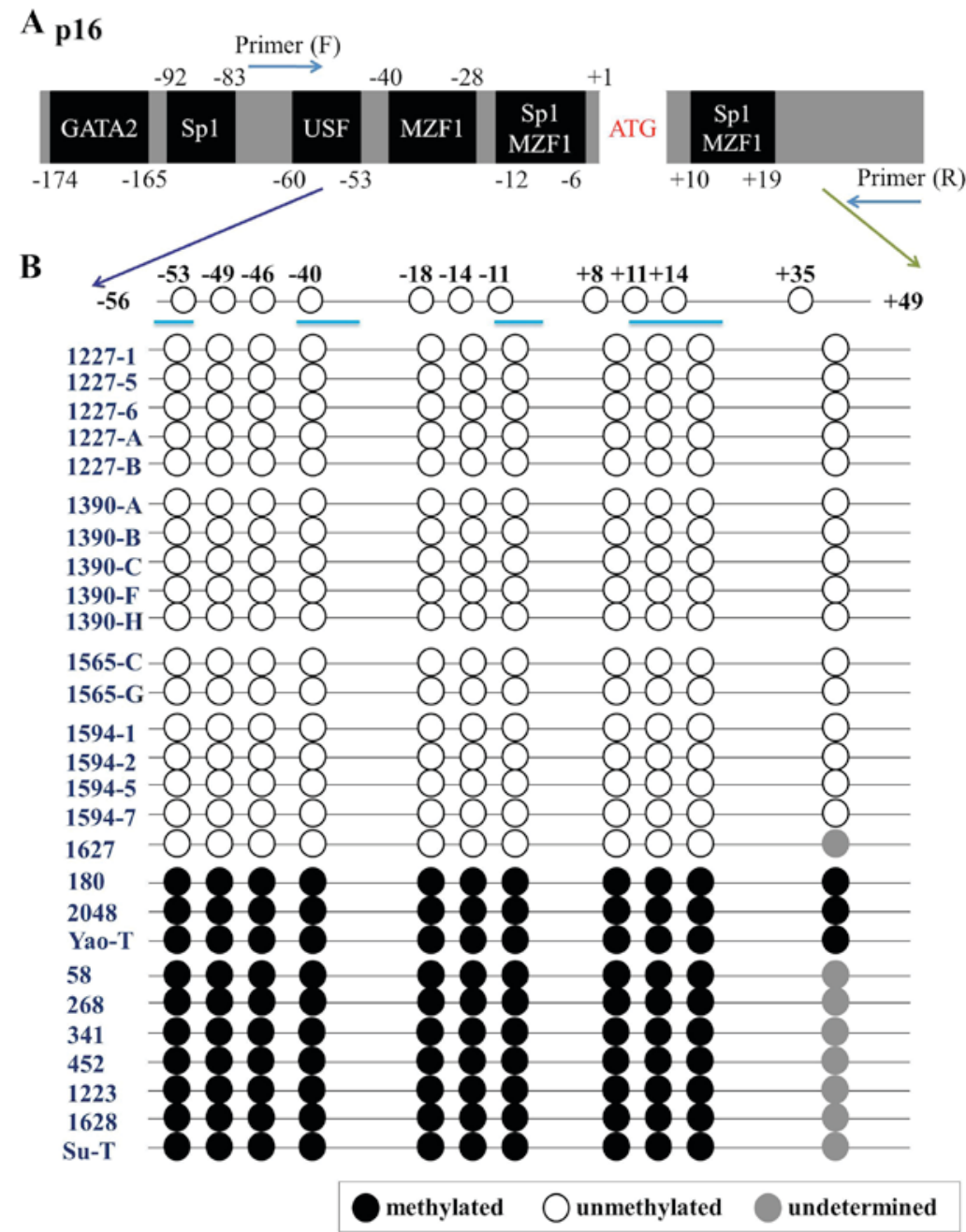

Figure 2. Bisulfite sequencing of p16 upstream sequences following bisulfite conversion. The 11 methylated $\mathrm{CpG}$ sites are located at the p16 promoter region. The gray bar indicates the transcription factor-binding sites in CpG. GATA2, GATA-binding protein 2; MZF1, myeloid zinc finger 1; Sp1, specificity protein 1; USF, upstream transcription factor 1 .

frequencies. Inflammation has numerous tumor-promoting effects in the tumor microenvironment. COX-2 has been established as one of the inflammatory factors involved in the process of angiogenesis and cell adhesion (21). A previous study reported that COX-2 expression was associated with higher grades of oral epithelial dysplasia (22). Jo et al (16) also reported that COX-2 is hypermethylated in cervical cancer, but their immunohistochemistry results did not demonstrate an association between hypermethylation and the expression pattern of COX-2. The present study revealed that all COX-2 genes were in an unmethylated form throughout the stages of CIN.

$\mathrm{CDH} 1$, also termed E-cadherin, is one of the molecules involved in the Wnt signaling cascade pathway (23). CDH1 methylation was detected in $43 \%$ (40/93) of serum samples of patients with cervical cancer (24). Chen et al (25) demonstrated that the inactivation of $\mathrm{CDH} 1$ is due to hypermethylation at the promoter region. Narayan et al (18) identified a high degree of methylation of CDH1 in cervical cancers $(51.1 \%$ of 90 cases); however, only 28.8 and $19.2 \%$ methylation was identified in the studies of Dong et al (26) and Feng et al (11), respectively. By contrast, in the present study, it was observed that the average methylation frequency of $\mathrm{CDH} 1$ was $4.5 \%$ in normal and CIN I, 7.1\% in CIN II and 7.9\% in CIN III. The methylation rate was markedly increased $<2$-fold between CIN I and carcinoma. It was observed that CDH1 exhibited a tendency to increased frequency of promoter methylation with increasing severity of cervical neoplasm changes. The degree of promoter methylation was proposed as a potential marker of the early events of tumorigenesis.

Aberrant methylation of the p16 gene is widely detected in the majority of types of tumor, and is the most studied tumor suppressor gene in cervical cancers (27). p16 is a cell cycle regulatory gene, and it performs an essential role in inhibiting cell abnormal growth. Its function is involved in the inhibition of cell cycle progression by encoding an inhibitor of cyclin-dependent kinase (CDK) 4 and CDK6 (28). Wong et al (29) and Dong et al (26) detected 31.6\% (31/98) and $30 \%(16 / 53)$ of methylated p16 in squamous cervical carcinoma, respectively. The results of the present study identified that the methylation frequency of p16 was relatively low in precancerous stages, and that the methylation frequency was increased in CIN II and CIN III. The methylation frequency of p16 was progressively increased during the development of malignant stages in CIN (Table I).

In the presence of HR-HPV, p16 exhibited a significant decrease in the methylation level between normal and CIN I 
$(\mathrm{P}<0.001)$. However, between CIN I and CIN II-carcinoma, the rate increased to $23.8 \%$. Most notably, in the absence of HR-HPV, the methylation frequency of p16 was $11.8 \%$ in normal, $25 \%$ in CIN I and $58.3 \%$ in CIN II-carcinoma. The methylation frequency of p16 was markedly increased between normal and CIN I, and between CIN I and CIN II-carcinoma. It was concluded that p16 methylation exhibited an apparent increase between normal and CIN I, and between CIN I and CIN II-carcinoma, without the intervention of virus infection. Furthermore, peripheral blood DNA obtained from patients was analyzed for the levels of p16 methylation, however no association was identified between these results and the DNA from the cervical cells (data not shown). p16 exerted a critical role across the cervical histological grades. However, in the presence of HR-HPV, methylation of p16 served no role in the stages of oncogenesis. It was hypothesized that virus infection or integration of viral genome may activate the oncogenic expression of p16 (30).

In conclusion, the results of the present study revealed that the methylation frequencies of p16 and CDH1 were progressively methylated in association with the development of malignant stages in CIN. Promoter methylation analysis of cervical cell specimens of p16 and CDH1 may be an additional diagnostic tool for current cervical cytomorphology-based screening and prognosis markers.

\section{Acknowledgements}

The present study was supported by the Taiwan National Science Council (grant no. NSC102-2314-B037-070-MY3), the National Health Research Institutes (grant no. NHRI-EX102-10226 PC) and the Kaohsiung Medical University Aim for the Top Universities Grant (grant no. KMU-TP105A00).

\section{References}

1. Bray F, Ren JS, Masuyer E and Ferlay J: Global estimates of cancer prevalence for 27 sites in the adult population in 2008. Int J Cancer 132: 1133-1145, 2013

2. Dijkstra MG, Snijders PJ, Arbyn M, Rijkaart DC, Berkhof J and Meijer CJ: Cervical cancer screening: On the way to a shift from cytology to full molecular screening. Ann Oncol 25: 927-935, 2014.

3. Snijders PJ, Steenbergen RD, Heideman DA and Meijer CJ: HPV-mediated cervical carcinogenesis: Concepts and clinical implications. J Pathol 208: 152-164, 2006.

4. Burd EM: Human papillomavirus and cervical cancer. Clin Microbiol Rev 16: 1-17, 2003

5. Ostör AG: Natural history of cervical intraepithelial neoplasia: A critical review. Int J Gynecol Pathol 12: 186-192, 1993.

6. Daniel FI, Cherubini K, Yurgel LS, de Figueiredo MA and Salum FG: The role of epigenetic transcription repression and DNA methyltransferases in cancer. Cancer 117: 677-687, 2011.

7. Bestor TH: The DNA methyltransferases of mammals. Hum Mol Genet 9: 2395-2402, 2000.

8. Esteller M: Epigenetics in cancer. N Engl J Med 358: 1148-1159, 2008.

9. Feinberg AP and Tycko B: The history of cancer epigenetics. Nat Rev Cancer 4: 143-153, 2004.

10. Cohen Y, Singer G, Lavie O, Dong SM, Beller U and Sidransky D: The RASSF1A tumor suppressor gene is commonly inactivated in adenocarcinoma of the uterine cervix. Clin Cancer Res 9: 2981-2984, 2003.
11. Feng Q, Balasubramanian A, Hawes SE, Toure P, Sow PS, Dem A, Dembele B, Critchlow CW, Xi L, Lu H, et al: Detection of hypermethylated genes in women with and without cervical neoplasia. J Natl Cancer Inst 97: 273-282, 2005.

12. Kang S, Kim HS, Seo SS, Park SY, Sidransky D and Dong SM: Inverse correlation between RASSF1A hypermethylation, KRAS and BRAF mutations in cervical adenocarcinoma. Gynecol Oncol 105: 662-666, 2007.

13. Wisman GB, Nijhuis ER, Hoque MO, Reesink-Peters N, Koning AJ, Volders HH, Buikema HJ, Boezen HM, Hollema H, Schuuring E, et al: Assessment of gene promoter hypermethylation for detection of cervical neoplasia. Int J Cancer 119: 1908-1914, 2006.

14. Wentzensen N, Sherman ME, Schiffman M and Wang SS: Utility of methylation markers in cervical cancer early detection: Appraisal of the state-of-the-science. Gynecol Oncol 112: 293-299, 2009.

15. Tsai HT, Tsai YM, Yang SF, Wu KY, Chuang HY, Wu TN, Ho CK, Lin CC, Kuo YS and Wu MT: Lifetime cigarette smoke and second-hand smoke and cervical intraepithelial neoplasm-a community-based case-control study. Gynecol Oncol 105: 181-188, 2007.

16. Jo H, Kang S, Kim JW, Kang GH, Park NH, Song YS, Park SY, Kang SB and Lee HP: Hypermethylation of the COX-2 gene is a potential prognostic marker for cervical cancer. J Obstet Gynaecol Res 33: 236-241, 2007.

17. Kang GH, Lee S, Lee HJ and Hwang KS: Aberrant CpG island hypermethylation of multiple genes in prostate cancer and prostatic intraepithelial neoplasia. J Pathol 202: 233-240, 2004.

18. Narayan G, Arias-Pulido H, Koul S, Vargas H, Zhang FF, Villella J, Schneider A, Terry MB, Mansukhani M and Murty VV: Frequent promoter methylation of CDH1, DAPK, RARB and HICl genes in carcinoma of cervix uteri: Its relationship to clinical outcome. Mol Cancer 2: 24, 2003.

19. Germain P, Chambon P, Eichele G, Evans RM, Lazar MA, Leid M, De Lera AR, Lotan R, Mangelsdorf DJ and Gronemeyer H: International union of pharmacology. LX. retinoic acid receptors. Pharmacol Rev 58: 712-725, 2006.

20. Alvarez S, Germain P, Alvarez R, Rodriguez-Barrios F, Gronemeyer $\mathrm{H}$ and de Lera AR: Structure, function and modulation of retinoic acid receptor beta, a tumor suppressor. Int $\mathrm{J}$ Biochem Cell Biol 39: 1406-1415, 2007.

21. Mantovani A, Allavena P, Sica A and Balkwill F: Cancer-related inflammation. Nature 454: 436-444, 2008.

22. Wang Z: The role of COX-2 in oral cancer development and chemoprevention/treatment of oral cancer by selective COX-2 inhibitors. Curr Pharm Des 11: 1771-1777, 2005.

23. Warner DR, Smith SC, Smolenkova IA, Pisano MM and Greene RM: Inhibition of p300 histone acetyltransferase activity in palate mesenchyme cells attenuates Wnt signaling via aberrant E-cadherin expression. Exp Cell Res 342: 32-38, 2016.

24. Widschwendter A, Ivarsson L, Blassnig A, Müller HM, Fiegl H, Wiedemair A, Müller-Holzner E, Goebel G, Marth C and Widschwendter M: CDH1 and CDH13 methylation in serum is an independent prognostic marker in cervical cancer patients. Int J Cancer 109: 163-166, 2004.

25. Chen CL, Liu SS, Ip SM, Wong LC, Ng TY and Ngan HY: E-cadherin expression is silenced by DNA methylation in cervical cancer cell lines and tumours. Eur J Cancer 39: 517-523, 2003.

26. Dong SM, Kim HS, Rha SH and Sidransky D: Promoter hypermethylation of multiple genes in carcinoma of the uterine cervix. Clin Cancer Res 7: 1982-1986, 2001.

27. Herman JG, Merlo A, Mao L, Lapidus RG, Issa JP, Davidson NE, Sidransky D and Baylin SB: Inactivation of the CDKN2/p16/MTS1 gene is frequently associated with aberrant DNA methylation in all common human cancers. Cancer Res 55: 4525-4530, 1995.

28. Serrano M: The tumor suppressor protein p16INK4a. Exp Cell Res 237: 7-13, 1997.

29. Wong YF, Chung TK, Cheung TH, Nobori T, Yu AL, Yu J, Batova A, Lai KW and Chang AM: Methylation of p16INK4A in primary gynecologic malignancy. Cancer Lett 136: 231-235, 1999.

30. Yamamoto A, Kumakura S, Uchida M, Barrett JC and Tsutsui T: Immortalization of normal human embryonic fibroblasts by introduction of either the human papillomavirus type $16 \mathrm{E} 6$ or E7 gene alone. Int J Cancer 106: 301-309, 2003. 